\title{
Aspirin and other non-steroidal anti-inflammatory drug use and colorectal cancer survival: a cohort study
}

\author{
AJ Walker,', MJ Grainge' and TR Card' \\ 'Division of Epidemiology and Public Health, School of Community Health Sciences, University of Nottingham, Nottingham City Hospital, Clinical Sciences \\ Building, $077 / 3$ 152268, Nottingham NG5 IPB, UK
}

\begin{abstract}
BACKGROUND: Aspirin has been widely reported to reduce the incidence of colorectal cancer. Recently, a survival benefit after diagnosis has also been suggested. Data regarding such a benefit are to date contradictory. This study examines the effect of nonsteroidal anti-inflammatory drug (NSAID) use on mortality in colorectal cancer in a larger patient cohort than previously to further clarify this effect, especially in terms of exposure timing and dosing.

METHODS: A study using the General Practice Research Database assessed whether aspirin or NSAID exposure in the year immediately following diagnosis affected all-cause mortality in a cohort of I 3994 colorectal cancer patients. Cox proportional hazards modelling adjusted for age, gender, smoking, body mass index and comorbidity.

RESULTS: Overall mortality was slightly lower in patients treated with aspirin, (hazard ratio $(H R)=0.91$; $95 \%$ confidence interval $(\mathrm{Cl})=0.82-1.00)$. This effect was observed only in patients treated with prophylaxis-dose aspirin $(\mathrm{HR}=0.89, \mathrm{Cl}=0.80-0.98)$ and only in patients taking aspirin before diagnosis $(H R=0.86, \mathrm{Cl}=0.76-0.98)$. Differential effects were observed depending on the time after diagnosis. Up to 5 years, a reduction in mortality was observed for aspirin users $(\mathrm{HR}=0.83, \mathrm{Cl}=0.75-0.92)$, whereas after 10 years there was an increase in mortality $(H R=1.94, \mathrm{Cl}=1.26-2.99)$. For NSAID use, no significant effect was observed on overall mortality $(H R=1.07, \mathrm{Cl}=0.98-1.15)$. High-dose NSAID use was associated with a slight increase in mortality $(H R=|.4|$, $\mathrm{Cl}=1.26-\mid .56)$.

INTERPRETATION: These findings provide further indication that aspirin may be beneficial in reducing mortality in colorectal cancer during the first 5 years. The same cannot be said for other NSAIDs, where a small increase in mortality was observed.

British Journal of Cancer (2012) I 07, 1602-1607. doi:I0.1038/bjc.2012.427 www.bjcancer.com

Published online 25 September 2012

(C) 2012 Cancer Research UK
\end{abstract}

Keywords: aspirin; NSAID; colorectal cancer; GPRD

Although some targeted agents, such as bevacizumab, are beginning to be used in colorectal cancer chemotherapy (Welch et al, 2010), conventional chemotherapeutic drugs including 5FU, capecitabine and oxaliplatin are still the mainstay of chemotherapy in this disease. Such drugs are known for their unpleasant side effects with even the more benign regimes (such as single agent capecitabine) producing diarrhoea in around $45 \%$ of patients, skin disorders like hand and foot syndrome in about 50\%, and adverse effects requiring hospitalisation in over $10 \%$ (Van Cutsem et al, 2001). Hence, alternative drugs with improved side effect profiles would be of great value.

Aspirin and non-aspirin non-steroidal anti-inflammatory drugs (NSAIDs) have well-recognised chemo-preventive effects against colorectal cancer (Dubé et al, 2007; Cuzick et al, 2009; Elwood et al, 2009; Half et al, 2009; Iwama and Iwama, 2009; Zell et al, 2009). It was long argued that for aspirin, this effect existed only at high doses, although recent evidence has emerged to suggest that prophylaxis dose (75 mg per day) aspirin may also be efficacious (Din et al, 2010; Rothwell et al, 2010). Other recent evidence has shown that those taking NSAIDs before diagnosis have improved survival after diagnosis of colorectal cancer (Zell et al, 2009; Coghill et al, 2010).

*Correspondence: Dr AJ Walker; E-mail: alex.walker@nottingham.ac.uk Received I June 2012; revised 17 August 2012; accepted 24 August 2012; published online 25 September 2012
These effects naturally lead to the question of whether these drugs may be of benefit as an adjuvant treatment in colorectal cancer. Recent studies have suggested that there may be a reduction in mortality for patients with colorectal cancer who have been treated with aspirin or NSAIDs (Chan et al, 2009; Bastiaannet et al, 2012). In both studies, the effect was seen in those treated with aspirin after diagnosis and the greatest effects were observed in patients who began aspirin use post diagnosis. The Chan et al (2009) study showed patients with tumours expressing high levels of cyclooxygenase-2 (COX-2) benefited most from aspirin use. We have endeavoured to clarify whether aspirin and other NSAIDs truly do have a potential as anti-neoplastics in diagnosed colorectal cancer in a larger cohort.

\section{MATERIALS AND METHODS}

\section{Study design}

A cohort study was carried out in the General Practice Research Database (GPRD) to determine the relationship between aspirin and NSAID usage and survival post cancer diagnosis.

\section{The GPRD}

The GPRD is a prospectively gathered, anonymised database encompassing around $500 \mathrm{GP}$ practices throughout the UK, and is 
the largest of its type in the world, with around 45 million patient years of data spread across approximately 6.5 million patients. It provides data on patients including clinical diagnoses, treatments and outcomes. The database was established in 1987, with its development corresponding to the increased computerisation of GP practices, and its validity having been well documented in a number of studies (Jick et al, 1991, 2003; Fombonne et al, 2004; Herrett et al, 2010), including a recent study validating cancer diagnosis and death (Dregan et al, 2012).

\section{Study population}

We selected any person with a recorded diagnosis of colorectal cancer within the GPRD (diagnosis codes available on request) occurring at least 1 year after their entry to the database. Patient data were collected from 1987, up to the latest available data (2010). Patients with a previous diagnosis of colorectal cancer were excluded from the cohort, as were patients contributing less than 1 year of data to the GPRD.

\section{Outcomes and exposures}

The outcome to be observed was all-cause mortality. Date of patient death was determined from the existence of one of two records; either a patient with a 'transfer out reason' specified as 'death'; or by a 'statement of death' (SoD) code (a 'clinical' or 'referral' event with a Read/OXMIS code indicating a death). Where both records existed, the date of death was determined preferentially from the SoD code. The follow-up time was determined to be the time between diagnosis, and the death date determined by the above method. Follow-up time for patients not dying in the study was determined either from the date that the patient transferred out from the GP or by the last data collection date for the GP.

The primary exposure was the use of aspirin, or another NSAID excluding aspirin (section 10.01.01 of the British National Formulary (BNF)). These two exposure groups (aspirin and other NSAIDs) were not mutually exclusive in that a patient could be counted as exposed to both. To be exposed, a patient must have had a repeat prescription $(\geqslant 2)$ within the period being examined for exposure. To minimise the risk of reverse causality (with patients dying early having less opportunity to receive a prescription), a fixed period of 1 year post-diagnosis was used to determine drug exposure, and patients who died or were censored within this period were excluded from the analysis.

Potential associations were examined further by investigating the dose used. For aspirin, prophylaxis dose was defined as $75 \mathrm{mg}$ or under per day, and high dose as anything over $75 \mathrm{mg}$. Where multiple prescriptions with differing doses existed, the most frequently prescribed dose was used. To allow comparison of the effect of high and low doses across all other NSAIDs as a group, we standardised our definition of high dose and low dose between drugs relative to the maximum recommended doses for each drug (determined from the BNF). These standardised doses were then used to calculate the mean dose across all prescriptions for each patient individually. Patients with NSAID use were divided into 'high'-dose or 'low'-dose groups based on the median corrected dose of 0.32 times maximum recommended dose.

We considered pre-diagnosis exposure as a potential effect modifier to determine whether it influenced the effect of postdiagnosis exposure.

\section{Other covariates}

We extracted data on gender, age, smoking status, alcohol use, body mass index (BMI) and comorbidity (coded as the Charlson index (Charlson et al, 1987)). Of these potential confounders, gender, age, comorbidity and smoking status were retained in multivariate models as a priori predictors of mortality risk. Other covariates were only retained in the multivariate model if they produced a $10 \%$ or greater change in the measured size of effect. Missing data were addressed by including a 'missing' category so that any such patients were not discounted from the analyses.

\section{Statistical methods}

We used Cox proportional hazards modelling to assess the effect of aspirin/NSAIDs on mortality risk, adjusting for multiple potential confounding variables as described above. Results are presented as hazard ratios (HR), with accompanying 95\% confidence intervals (CIs). We examined the potential for effect modification by prior aspirin use via a stratified analysis and the fitting of interaction terms in our Cox model.

Validity of the proportional hazards assumption was tested using a log-cumulative hazard plot. Due to violation of the proportional hazards assumption in the present analysis, we subsequently performed a stratified analysis, detailing the mortality risks based on aspirin use, separately for the first 5 years following cancer diagnosis, 5-10 years following diagnosis and $>10$ years following diagnosis.

All data handling and analysis was done using Stata v11.1 SE (StataCorp., College Station, TX, USA).

\section{RESULTS}

We identified 13944 patients with colorectal cancer, 5358 (38.4\%) of these patients died during their period of registration and their median follow-up time (survival time) for this group was 1.7 years. The remaining patients, alive up to the end of follow-up, had a median time of post-diagnosis follow-up of 3.1 years (interquartile range 1.3-6.2). Aspirin use between diagnosis and 12 months post diagnosis was at $18.8 \%$ in patients surviving more than 12 months after diagnosis. A total of $26.1 \%$ of patients received a prescription for aspirin pre-diagnosis. These results are summarised, along with other covariates used in the study in Table 1.

We found that post diagnosis, aspirin use (Table 2) was associated with a decrease in mortality in colorectal cancer patients (multivariate $\mathrm{HR}=0.91, \mathrm{CI}=0.82-1.00$ ). This effect was not observed in patients not using aspirin before diagnosis ( $\mathrm{HR}=0.99, \mathrm{CI}=0.84-1.16)$, whereas there was an effect observed in patients who did use aspirin pre-diagnosis $(\mathrm{HR}=0.86$, $\mathrm{CI}=0.76-0.98)$. If pre-diagnosis aspirin use is considered exclusively, there was no association with survival $(\mathrm{HR}=1.04$, $\mathrm{CI}=0.97-1.12$ ). In this latter case, we included all patients excluded from the analyses due to surviving less than 1 year.

With NSAID use, there was a statistically significant increase in mortality when all patients were considered together $(\mathrm{HR}=1.29$, $\mathrm{CI}=1.18-1.42)$. However, there was a greater increase in mortality observed in those beginning NSAID use after diagnosis, having not used them before diagnosis $(\mathrm{HR}=1.69, \mathrm{CI}=1.45-1.97)$. As with aspirin, no statistically significant effects were observed when pre-diagnosis exposure only was considered $(\mathrm{HR}=1.05$, $\mathrm{CI}=0.99-1.12$ ).

Investigation of the effect of dose is presented in Table 3. For aspirin, a dose-response effect was not observed, as there was a small, non-significant decrease in mortality in those using prophylaxis-dose aspirin ( $\mathrm{HR}=0.94, \mathrm{CI}=0.86-1.02)$ and a small, non-significant increase in mortality in patients using high-dose aspirin $(\mathrm{HR}=1.13, \mathrm{CI}=0.97-1.32)$. These observations were largely repeated for NSAID use, although for high-dose NSAIDs, a significant and greater increase in mortality was observed $(\mathrm{HR}=1.41, \mathrm{CI}=1.26-1.56)$.

If the original analysis (Table 2) is repeated with patients using high dose post diagnosis aspirin/NSAID excluded from the study, the results are broadly similar for aspirin, but with slightly greater 
Table I Covariates

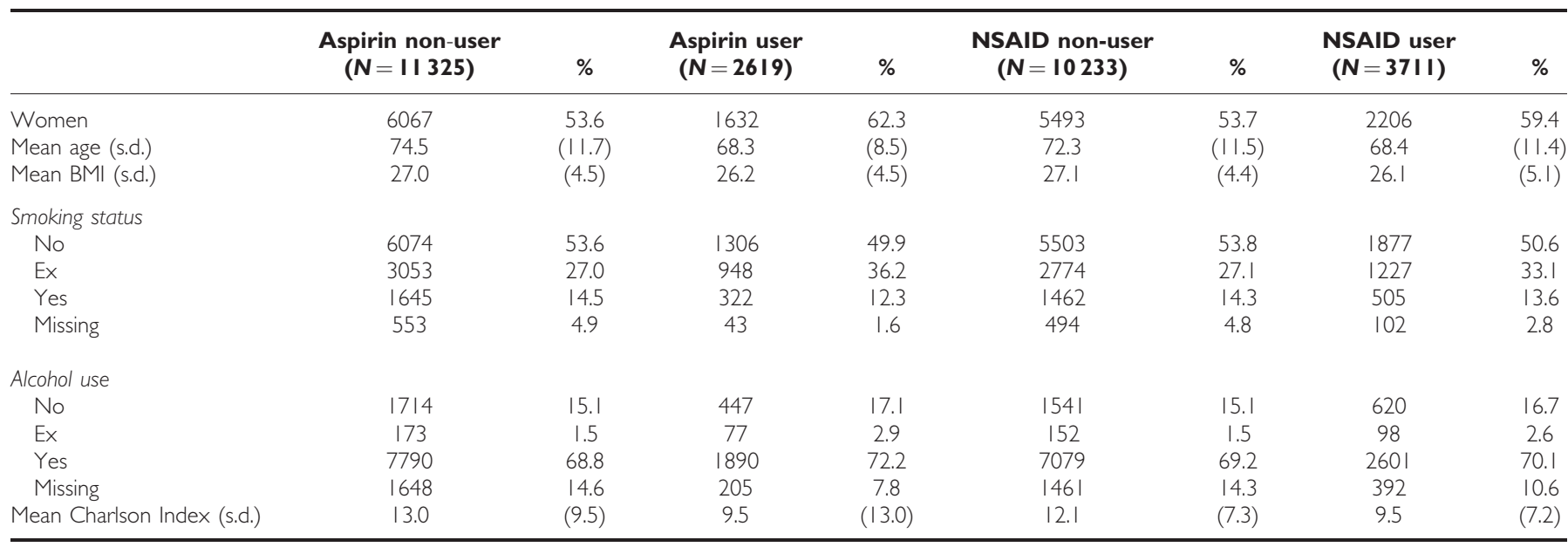

Numbers in table represent $\mathrm{N}$ (\%) for categorical variables and mean (s.d.) for continuous variables.

Table 2 Risk of all-cause mortality according to use of aspirin or NSAIDs after diagnosis

\begin{tabular}{|c|c|c|c|c|c|c|}
\hline & $\begin{array}{c}\text { Aspirin } \\
\text { non-user, HR }\end{array}$ & $\begin{array}{l}\text { Aspirin } \\
\text { user, HR }\end{array}$ & $(95 \% \mathrm{Cl})$ & $\begin{array}{c}\text { NSAID } \\
\text { non-user, HR }\end{array}$ & $\begin{array}{l}\text { NSAID } \\
\text { user, HR }\end{array}$ & $(95 \% \mathrm{Cl})$ \\
\hline \multicolumn{7}{|l|}{ All participants } \\
\hline Age-adjusted HR & I (Ref) & 0.94 & $(0.87,1.01)$ & I (Ref) & 1.06 & $(1.00,1.13)$ \\
\hline Age and pre-diagnosis drug use adjusted HR & I (Ref) & 0.89 & $(0.81,0.98)$ & I (Ref) & 1.08 & $(1.00,1.16)$ \\
\hline Multivariate $\mathrm{HR}^{\mathrm{a}}$ & I (Ref) & 0.91 & $(0.82,1.00)$ & I (Ref) & 1.07 & $(0.98,1.15)$ \\
\hline \multicolumn{7}{|l|}{ Aspirin/NSAID non-users pre-diagnosis } \\
\hline Multivariate $\mathrm{HR}^{\mathrm{a}}$ & I (Ref) & 0.99 & $(0.84,1.16)$ & I (Ref) & 1.46 & $(1.27,1.67)$ \\
\hline \multicolumn{7}{|l|}{ Aspirin/NSAID users pre-diagnosis } \\
\hline Deaths/number remaining alive & $490 / 694$ & $766 / 1377$ & & |523/2648 & | I 45/1959 & \\
\hline Age-adjusted HR & I (Ref) & 0.84 & $(0.75,0.94)$ & I (Ref) & 0.97 & $(0.9,1.05)$ \\
\hline Multivariate $\mathrm{HR}^{\mathrm{a}}$ & I (Ref) & 0.86 & $(0.76,0.98)$ & I (Ref) & 0.95 & $(0.87,1.03)$ \\
\hline
\end{tabular}

Abbreviations: $\mathrm{Cl}=$ confidence interval; $\mathrm{HR}=$ hazard ratio. ${ }^{a}$ Adjusted for: age, gender, smoking, $\mathrm{BMI}$, alcohol use and comorbidity (Charlson index).

Table 3 Risk of all-cause mortality according to dose of post diagnosis aspirin or NSAIDs use

\begin{tabular}{|c|c|c|c|c|c|}
\hline \multirow[b]{2}{*}{ Drug type } & \multirow[b]{2}{*}{ Exposure } & \multicolumn{2}{|c|}{ Age adjusted } & \multicolumn{2}{|c|}{ Multivariate $^{a}$} \\
\hline & & HR & $(95 \% \mathrm{Cl})$ & HR & $(95 \% \mathrm{Cl})$ \\
\hline Aspirin & $\begin{array}{l}\text { Unexposed } \\
\text { Prophylaxis dose } \\
\text { High dose }\end{array}$ & $\begin{array}{l}1 \\
0.91 \\
1.10\end{array}$ & $\begin{array}{l}(0.84,0.98) \\
(0.95,1.27)\end{array}$ & $\begin{array}{l}1 \\
0.94 \\
1.13\end{array}$ & $\begin{array}{l}(0.86,1.02) \\
(0.97,1.32)\end{array}$ \\
\hline NSAIDs & $\begin{array}{l}\text { Unexposed } \\
\text { Low dose } \\
\text { High dose }\end{array}$ & $\begin{array}{l}1 \\
0.94 \\
1.42\end{array}$ & $\begin{array}{l}(0.87,1.01) \\
(1.29,1.57)\end{array}$ & $\begin{array}{l}1 \\
0.96 \\
1.41\end{array}$ & $\begin{array}{l}(0.89,1.04) \\
(1.26,1.56)\end{array}$ \\
\hline
\end{tabular}

Abbreviations: $\mathrm{Cl}=$ confidence interval; $\mathrm{HR}=$ hazard ratio. ${ }^{\mathrm{a} A d j u s t e d ~ f o r: ~ a g e, ~}$ gender, smoking, BMI, alcohol use and comorbidity (Charlson index)

size of effect (Table 4). For NSAIDs, the increase in mortality previously observed in patients who had not used them before diagnosis was reduced somewhat, though still significant $(\mathrm{HR}=1.25, \mathrm{CI}=1.04-1.49)$.

We investigated the differences between different anatomical sites of the cancer by dividing them into colon and rectal cancers. This gave proportions similar to UK incidence data (Cancer Research UK) with $61.0 \%$ colonic, $33.9 \%$ rectal and $5.1 \%$ unspecified site. However, we found that the overall multivariate HRs did not differ substantially between sites (colonic $\mathrm{HR}=0.89$, $\mathrm{CI}=0.79-1.01 ; \quad$ rectal $\quad \mathrm{HR}=0.92, \quad \mathrm{CI}=0.77-1.09 ; \quad$ unknown $\mathrm{HR}=0.90, \mathrm{CI}=0.59-1.38)$.

Examination of the proportional hazards assumption revealed a clear violation in the models. The HRs clearly varied with time, as the log-log plots cross at around 6.3 years. This change can be seen in Figure 1A. We therefore formed separate models for 0-5 years, $5-10$ years and $>10$ years follow-up after diagnosis (Table 5). For aspirin, a reduction in mortality was observed up to 5 years $(\mathrm{HR}=0.83, \mathrm{CI}=0.75-0.92)$, whereas after this point the effect became an increase in mortality, especially in the $>10$ years period $(\mathrm{HR}=1.95, \mathrm{CI}=1.27-2.99)$. Although NSAIDs did not display the same level of differential effects (Figure 1B), the analysis was carried out in the same way, though no notable trend was observed.

\section{DISCUSSION}

We have confirmed that there is a reduction in all-cause mortality in colorectal cancer patients who take aspirin for the 1 year after diagnosis. This benefit is modest with a HR of 0.91 overall in our multivariate model. Subgroup analyses showed that the benefit was confined to those who also used aspirin before diagnosis and who 
Table 4 Risk of all-cause mortality according to use of prophylaxis-dose aspirin or NSAIDs after diagnosis

\begin{tabular}{|c|c|c|c|c|c|c|}
\hline Pre-diagnosis exposure strata & $\begin{array}{c}\text { Aspirin } \\
\text { non-user, HR }\end{array}$ & $\begin{array}{c}\text { Low-dose } \\
\text { aspirin user, } H R\end{array}$ & $(95 \% \mathrm{Cl})$ & $\begin{array}{c}\text { NSAID } \\
\text { non-user, HR }\end{array}$ & $\begin{array}{l}\text { Low-dose } \\
\text { NSAID user, HR }\end{array}$ & $(95 \% \mathrm{Cl})$ \\
\hline \multicolumn{7}{|l|}{ All participants } \\
\hline Age-adjusted HR & I (Ref) & 0.91 & $(0.84,0.98)$ & I (Ref) & 0.94 & $(0.87,1.01)$ \\
\hline Age and pre-diagnosis drug use adjusted HR & I (Ref) & 0.86 & $(0.79,0.94)$ & I (Ref) & 0.94 & $(0.87,1.01)$ \\
\hline Multivariate $\mathrm{HR}^{\mathrm{a}}$ & I (Ref) & 0.89 & $(0.8,0.98)$ & I (Ref) & 0.94 & $(0.86,1.02)$ \\
\hline \multicolumn{7}{|l|}{ Aspirin/NSAID non-users pre-diagnosis } \\
\hline Multivariate $\mathrm{HR}^{\mathrm{a}}$ & I (Ref) & 0.99 & $(0.84,1.16)$ & I (Ref) & 1.25 & $(1.04,1.49)$ \\
\hline \multicolumn{7}{|l|}{ Aspirin/NSAID users pre-diagnosis } \\
\hline Deaths/number remaining alive & $490 / 694$ & $597 / 1176$ & & |523/2648 & $825 / 1522$ & \\
\hline Age-adjusted HR & I (Ref) & 0.81 & $(0.72,0.92)$ & I (Ref) & 0.89 & $(0.81,0.97)$ \\
\hline Multivariate $\mathrm{HR}^{\mathrm{a}}$ & I (Ref) & 0.83 & $(0.73,0.95)$ & I (Ref) & 0.88 & $(0.8,0.96)$ \\
\hline
\end{tabular}

Abbreviations: $\mathrm{Cl}=$ confidence interval; $\mathrm{HR}=$ hazard ratio. ${ }^{2}$ Adjusted for: age, gender, smoking, $\mathrm{BMl}$, alcohol use and comorbidity (Charlson index).

A

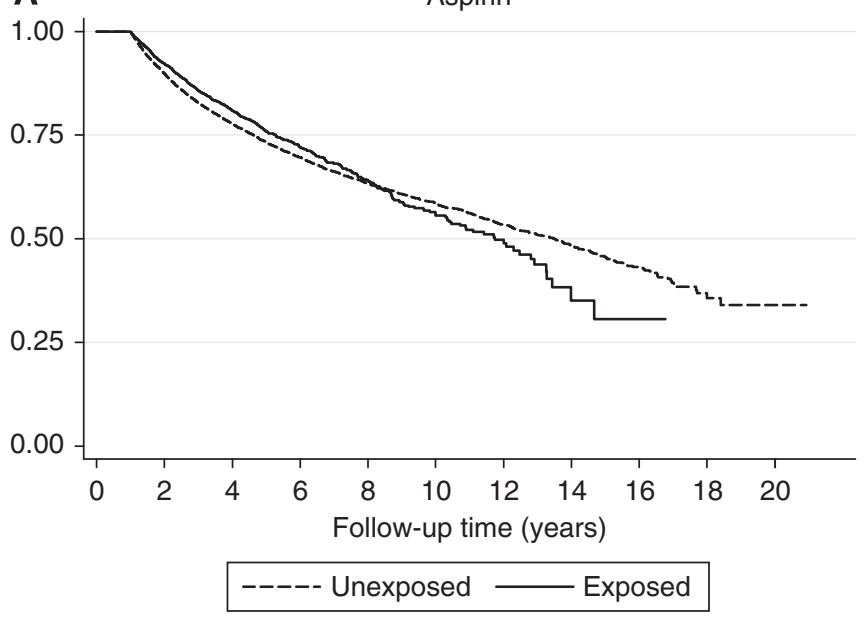

B

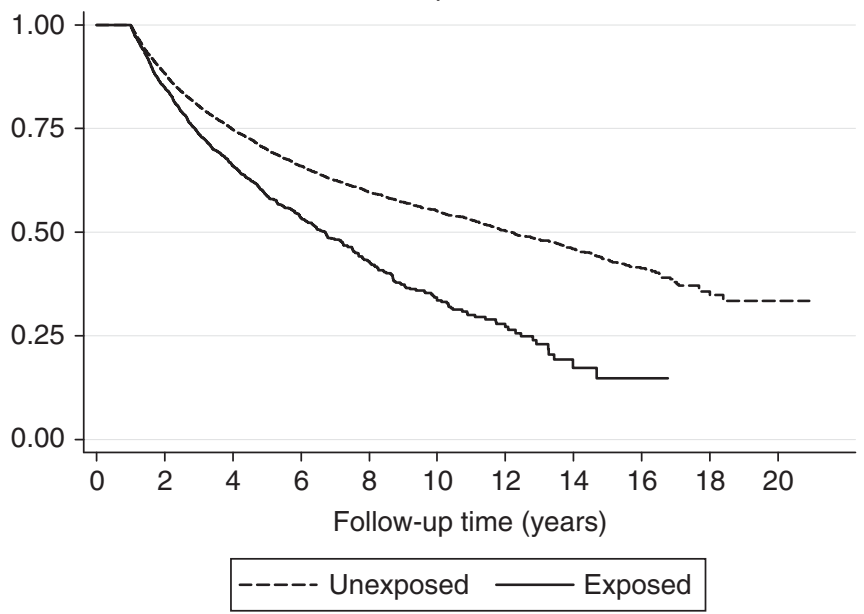

Figure I Survival according to aspirin/NSAID use after diagnosis. Multivariate colorectal cancer patient survival curves stratified according to aspirin (A) and NSAID (B) exposure. Adjusted for: age, gender, smoking, BMI, alcohol use and comorbidity (Charlson index).

took it in prophylaxis dose. The benefit was observed only in the period up to 5 years after diagnosis, after which point aspirin users suffered higher mortality. When our analysis was limited to the first 5 years after diagnosis and considering only prophylaxis-dose aspirin started before diagnosis, the HR was $0.79(\mathrm{CI}=0.71-0.89)$. Although this subgroup analysis is interesting, the clinical implications are unclear and must be interpreted with caution (see later discussion). No similar benefit was found with other NSAID use, and in contrast NSAID use was associated with a slight increase in mortality.

Our data do have certain important strengths. The data set in terms of numbers of cancers is far larger than any previous study of this subject. As our data are taken from a GP database, with practices spread across the UK, our results should be highly generalisable. In addition, by selecting all relevant malignancies within the population (rather than sampling a smaller proportion of the available colorectal cancers), we largely eliminated the possibility of selection bias. One potential remaining selection bias, however, relates to our exclusion of deaths in the first year of follow-up. This will undoubtedly have excluded some of the more aggressive cancers and it is possible that such tumours will be less likely to respond to aspirin. Our use of routinely collected general practice records (from the GPRD) ensured also that there was no opportunity for recall bias to effect the ascertainment of exposures. Data on prescribing in the GPRD is highly reliable due to their automatic recording upon prescription creation. However, over the counter purchase is not captured in the database, which may cause a slight null bias, though the size of this effect should be small given that patients over 60 (and some other patient groups) receive free prescriptions in the UK, and over $80 \%$ of this population are over 60 .

However, we cannot be equally confident about the recording of all potential confounders. There is some missing data with respect to smoking, obesity and alcohol, and due to the nature of these data recording of such factors is likely to be imperfect in terms of timing and consistency across GPs. There is therefore a potential for residual confounding by these factors. However, these factors, even when combined, had a relatively small confounding effect, and so it is likely that any residual confounding by these factors would be minor. We lack, however, any data on factors such as cancer stage, histological grade and COX2 expression (expression of COX-2 in a colorectal tumour has been shown to be associated with a greater decrease in mortality when taking aspirin (Chan et al, 2009)). Adjusting for these factors could therefore appreciably alter the size of our observed effects.

Likewise, though our adjustment for comorbidity via the Charlson index may have reduced the extent of residual confounding by morbidity, it is highly likely that comorbidity would lead to both increased aspirin or NSAID use (for pain management, for example) and increased mortality. Indeed, we believe this confounding by indication may explain interactions where aspirin or NSAIDs are associated with increases in mortality 
Table 5 Examination of differential early and late effects in risk of all-cause mortality according to post diagnosis use of aspirin or NSAIDs

\begin{tabular}{|c|c|c|c|c|c|c|}
\hline \multirow[b]{2}{*}{ Drug type } & \multirow[b]{2}{*}{ Period examined } & \multirow[b]{2}{*}{ Post diagnosis exposure } & \multicolumn{2}{|c|}{ Patient status at end of follow-up } & \multicolumn{2}{|c|}{ Multivariate $^{a}$} \\
\hline & & & Alive & Dead & HR & $(95 \% \mathrm{CI})$ \\
\hline \multirow[t]{6}{*}{ Aspirin } & $0-5$ years & Unexposed & 3885 & 3498 & I & \\
\hline & & Exposed & $1 \mid 43$ & 776 & 0.83 & $(0.75,0.92)$ \\
\hline & $5-10$ years & Unexposed & 2160 & 708 & । & \\
\hline & & Exposed & 440 & 156 & 1.28 & $(1.05,1.54)$ \\
\hline & $>10$ years & Unexposed & 880 & 194 & I & \\
\hline & & Exposed & 78 & 26 & 1.95 & $(1.27,2.99)$ \\
\hline \multirow[t]{6}{*}{ NSAIDs } & $0-5$ years & Unexposed & 4625 & 3780 & । & \\
\hline & & Exposed & 403 & 494 & 1.34 & $(1.21,1.49)$ \\
\hline & $5-10$ years & Unexposed & 2351 & 797 & । & \\
\hline & & Exposed & 249 & 67 & 0.99 & $(0.77,1.28)$ \\
\hline & $>10$ years & Unexposed & 886 & 196 & । & \\
\hline & & Exposed & 72 & 24 & 1.57 & $(1.01,2.42)$ \\
\hline
\end{tabular}

Abbreviations: $\mathrm{Cl}=$ confidence interval; $\mathrm{HR}=$ hazard ratio. ${ }^{\mathrm{a}}$ Adjusted for: age, gender, smoking, $\mathrm{BMl}$, alcohol use and comorbidity (Charlson index).

in some subsets of our data. To clarify further, we believe that it is likely that high-dose aspirin use and NSAID use are mainly indicated for pain. As this may well be an indication of advanced disease (via metastases, for example), it is unsurprising that we can show no benefit from these prescriptions. Likewise, new aspirin prescriptions at prophylaxis dose will most commonly occur because the prescriber has become aware of a new cardiovascular risk for mortality or morbidity and so we are unsurprised to be unable to show a benefit in those receiving aspirin only after cancer diagnosis (long standing risks for cardiovascular disease may be of less immediate mortality risk). This interpretation does make an assumption that indication can be defined by dose alone and so is somewhat speculative as this is not a perfect measure. However, we believe that, for example, the vast majority of people taking $75 \mathrm{mg}$ aspirin will not be using it as an analgesic.

In relation to previously published work on this subject, our results are broadly similar in that we found a decrease in mortality in aspirin users. The results were also similar in scale to comparable groups in other studies (Chan et al, 2009), which found around a $20-30 \%$ decrease in mortality. However, the results differ in some notable ways. For example, whereas Chan et al (2009) found their greatest size of effect in patients who started aspirin use for the first time post diagnosis, we found essentially no effect here. Whereas other studies were able to look at cancer specific mortality, due to limitations in the GPRD, our study looked at all-cause mortality. If our explanation of the lack of benefit of new prescriptions on all-cause mortality given in the previous paragraph is correct, this limitation of our study would explain this discrepancy. This might also explain the time course differences in the benefits that we observed. During the early years after cancer diagnosis (when we show a benefit on all-cause mortality), cancer-related mortality is likely to predominate. The later loss of this benefit then probably relates to the fact that at later stages, cardiovascular mortality (for which aspirin prescription will mark a risk) predominates as in the general population. That is, the change in effect over time reflects changes in the importance of our inability to correct perfectly for cardiovascular comorbidity. In contrast to the previous studies concentrating on a survival benefit of pre-diagnosis exposure, our results cannot be simply explained by aspirin/NSAIDs via GI toxicity prompting investigation and earlier diagnosis, as such an effect should be independent of post diagnosis exposure.

\section{REFERENCES}

Bastiaannet E, Sampieri K, Dekkers OM, de Craen AJM, van Herk-Sukel MPP, Lemmens V, van den Broek CBM, Coebergh JW, Herings RMC, van
Overall, therefore, we find the protective effect of aspirin in the early years after colorectal cancer diagnosis to be similar to that found in other studies and not wholly incomparable to the $35 \%$ reduction in death found in RCTs of chemotherapy drugs (Colorectal Cancer Collaborative Group, 2000). Aspirin is not without side effects, including gastrointestinal irritation and even haemorrhage. However, its toxicity is substantially lower than that for drugs with proven benefit in colorectal cancer such as fluoropyrimidines and oxaliplatin, whose side effects include neutropenia, increased risk of infection, nausea and vomiting, fatigue, alopecia and potential fertility loss.

The body of evidence for the anti-cancer effect of aspirin in colorectal cancer is ever expanding. Due to the limitations of this and previous studies, it would appear that randomised trials of its addition to standard care may well be the only way to better determine whether it can confer a benefit to cancer patients after diagnosis, and if so which patients are most likely to benefit. Given the potential gain for colorectal cancer patients, it would be imprudent to not investigate this further in patients.

\section{ACKNOWLEDGEMENTS}

This study is based in part on data from the General Practice Research Database obtained under licence from the UK Medicines and Healthcare Products Regulatory Agency. However, the interpretation and conclusions contained in this study are those of the authors alone. AJW was funded by a Medical Research Council (MRC) studentship. Access to the GPRD was provided by the licence agreement with the MRC. The MRC had no role in study design, data collection, analysis or interpretation of data.

\section{Conflict of interest}

The spouse of TRC is an employee of Astra Zeneca. The remaining authors declare no conflict of interest.

\section{Author contributions}

AJW and TRC conceived the project and designed the study. Analysis was carried out by AJW, MJG and TRC. AJW wrote the first draft under the supervision of MJG and TRC. All authors contributed to subsequent drafting. 
Chan AT, Ogino S, Fuchs CS (2009) Aspirin use and survival after diagnosis of colorectal cancer. JAMA 302(6): 649-658

Charlson ME, Pompei P, Ales KL, MacKenzie CR (1987) A new method of classifying prognostic comorbidity in longitudinal studies: development and validation. J Chronic Dis 40(5): 373-383

Coghill AE, Newcomb PA, Campbell PT, Burnett-Hartman AN, Adams SV, Poole EM, Potter JD, Ulrich CM (2010) Prediagnostic non-steroidal antiinflammatory drug use and survival after diagnosis of colorectal cancer. Gut 60(4): 491-498

Colorectal Cancer Collaborative Group (2000) Palliative chemotherapy for advanced colorectal cancer: systematic review and meta-analysis. $B m j$ 321(7260): 531-535

Cuzick J, Otto F, Baron JA, Brown PH, Burn J, Greenwald P, Jankowski J, La Vecchia C, Meyskens F, Senn HJ, Thun M, Cuzick J, Otto F, Baron JA, Brown PH, Burn J, Greenwald P, Jankowski J, La Vecchia C, Meyskens F, Senn HJ, Thun M (2009) Aspirin and non-steroidal anti-inflammatory drugs for cancer prevention: an international consensus statement. Lancet Oncol 10(5): 501-507

Din FV, Theodoratou E, Farrington SM, Tenesa A, Barnetson RA, Cetnarskyj R, Stark L, Porteous ME, Campbell H, Dunlop MG (2010) Effect of aspirin and NSAIDs on risk and survival from colorectal cancer. Gut 59(12): 1670-1679

Dregan A, Moller H, Murray-Thomas T, Gulliford MC (2012) Validity of cancer diagnosis in a primary care database compared with linked cancer registrations in England. Population-based cohort study. Cancer Epidemiol 36(5): 425-429

Dubé C, Rostom A, Lewin G, Tsertsvadze A, Barrowman N, Code C, Sampson M, Moher D (2007) The use of aspirin for primary prevention of colorectal cancer: a systematic review prepared for the U.S. Preventive Services Task Force. Ann Intern Med 146(5): 365-375

Elwood PC, Gallagher AM, Duthie GG, Mur LA, Morgan G, Elwood PC, Gallagher AM, Duthie GG, Mur LAJ, Morgan G (2009) Aspirin, salicylates, and cancer. Lancet 373(9671): 1301-1309

Fombonne E, Heavey L, Smeeth L, Rodrigues LC, Cook C, Smith PG, Meng L, Hall AJ, Fombonne E, Heavey L, Smeeth L, Rodrigues LC, Cook C,
Smith PG, Meng L, Hall AJ (2004) Validation of the diagnosis of autism in general practitioner records. BMC Public Health 4: 5

Half E, Arber N, Half E, Arber N (2009) Colon cancer: preventive agents and the present status of chemoprevention. Expert Opin Pharmacother 10(2): 211-219

Herrett E, Thomas SL, Schoonen WM, Smeeth L, Hall AJ (2010) Validation and validity of diagnoses in the General Practice Research Database: a systematic review. Br J Clin Pharmacol 69(1): 4-14

Iwama T, Iwama T (2009) NSAIDs and colorectal cancer prevention. J Gastroenterol 44(Suppl 19): 72-76

Jick H, Jick SS, Derby LE (1991) Validation of information recorded on general practitioner based computerised data resource in the United Kingdom. Bmj 302(6779): 766-768

Jick SS, Kaye JA, Vasilakis-Scaramozza C, Garcia Rodriguez LA, Ruigomez A, Meier CR, Schlienger RG, Black C, Jick H, Jick SS, Kaye JA, VasilakisScaramozza C, Garcia Rodriguez LA, Ruigomez A, Meier CR, Schlienger RG, Black C, Jick H (2003) Validity of the general practice research database. Pharmacotherapy 23(5): 686-689

Rothwell PM, Fowkes FGR, Belch JFF, Ogawa H, Warlow CP, Meade TW (2010) Effect of daily aspirin on long-term risk of death due to cancer: analysis of individual patient data from randomised trials. Lancet 377(9759): 31-41

Van Cutsem E, Twelves C, Cassidy J, Allman D, Bajetta E, Boyer M, Bugat R, Findlay M, Frings S, Jahn M, McKendrick J, Osterwalder B, Perez-Manga G, Rosso R, Rougier P, Schmiegel WH, Seitz J-F, Thompson P, Vieitez JM, Weitzel C, Harper P (2001) Oral capecitabine compared with intravenous fluorouracil plus leucovorin in patients with metastatic colorectal cancer: results of a large phase III study. J Clin Oncol 19(21): 4097-4106

Welch S, Spithoff K, Rumble RB, Maroun J (2010) Bevacizumab combined with chemotherapy for patients with advanced colorectal cancer: a systematic review. Ann Oncol 21(6): 1152-1162

Zell JA, Ziogas A, Bernstein L, Clarke CA, Deapen D, Largent JA, Neuhausen SL, Stram DO, Ursin G, Anton-Culver H (2009) Nonsteroidal anti-inflammatory drugs: effects on mortality after colorectal cancer diagnosis. Cancer 115(24): 5662-5671

This work is published under the standard license to publish agreement. After 12 months the work will become freely available and the license terms will switch to a Creative Commons Attribution-NonCommercial-Share Alike 3.0 Unported License. 